\title{
Indium Tin Oxide Modified by Au and Vanadium Pentoxide as an Efficient Anode for Organic Light-Emitting Devices
}

\author{
H. M. Zhang and Wallace C. H. Choy, Senior Member, IEEE
}

\begin{abstract}
Au/Vanadium pentoxide $\left(\mathrm{V}_{2} \mathrm{O}_{5}\right)$ films on indium tin oxide (ITO) as composite anodes for hole injection in organic light-emitting devices (OLEDs) have been investigated. The device with ITO/Au $(6 \mathrm{~nm}) / \mathrm{V}_{2} \mathrm{O}_{5}(6 \mathrm{~nm})$ anode shows improved current density-voltage characteristics as compared with the device with ITO/Au as anode. Hole injection is significantly reduced when Au was added on ITO as an anode. However, while a thin $\mathrm{V}_{2} \mathrm{O}_{5}$ film is deposited on a Au anode, the barrier height is substantially reduced. The hole injection is facilitated, and the driving voltage of the device decreased by $10 \mathrm{~V}$. In addition, the maximum current efficiency for the ITO/Au $/ \mathrm{V}_{2} \mathrm{O}_{5}$ OLED is $\sim 3.5 \mathrm{~cd} / \mathrm{A}$, which is higher than that of the ITO/Au anode device $(\sim 1.1 \mathrm{~cd} / \mathrm{A})$ and ITO $/ \mathrm{V}_{2} \mathrm{O}_{5}$ OLED of $\sim 2.8 \mathrm{~cd} / \mathrm{A}$.
\end{abstract}

Index Terms-Efficient anode, improved hole injection, organic light-emitting devices (OLEDs), reduced driving voltage.

C ONVENTIONAL bottom emitting organic light-emitting devices (OLEDs) commonly use conductive indium tin oxide (ITO) as anode because of its high conductivity, transparency, and work function. However, the surface of ITO glass is chemically and physically ill defined, which will degrade the performance as the hole-injecting electrode in OLEDs. Over the past years, many methods were used to treat the surface of ITO [1]-[5], such as ultraviolet-ozone cleaning and oxygen plasma exposure, in order to enhance hole injection [1], [2]. These treatments were effective in removing residual surface contaminants and increasing oxygen content at ITO surface, resulting in the increase of work function to minimize interfacial charge injection barriers.

Moreover, the incorporation of injection enhancing interlayer at electrode-organic interfaces has been used as one alternative route to control carrier injection [6], [7]. Using metal oxides with high work function, such as $\mathrm{AgO}_{x}$ [8] and $\mathrm{NiO}_{x}$ [9], as an interfacial layer between ITO and organic material has

Manuscript received April 2, 2008. This work was supported by the Research Grant Council of the HK Special Administrative Region, China, under Grant 14300.324.01. The review of this brief was arranged by Editor L. Lunardi.

H. M. Zhang is with the State Key Laboratory of Polymer Physics and Chemistry, Changchun Institute of Applied Chemistry, Chinese Academy of Sciences, Changchun 130022, China, and also with the Department of Electrical and Electronic Engineering, The University of Hong Kong, Hong Kong.

W. C. H. Choy is with the Department of Electrical and Electronic Engineering, The University of Hong Kong, Hong Kong, and also with the Department of Materials Science and Engineering, Cornell University, Ithaca, NY 148531501 USA (email: chchoy@eee.hku.hk).

Digital Object Identifier 10.1109/TED.2008.927387 been proven to enhance hole-injection efficiencies. Vanadium pentoxide $\left(\mathrm{V}_{2} \mathrm{O}_{5}\right)$ is a $p$-type semiconductor [10] with a high work function of $\sim 5.4 \mathrm{eV}$ [11]. It has also been used as an efficient modification layer of ITO and ( $p$-Si) anode to enhance hole injection [12], [13]. In addition, many high work function metals such as Ag and Au [14], [15] have been studied as the anode materials. However, they are not suitable for the anode as the hole injection is virtually blocked when the metal anodes are used [16]-[18]. The reports generally concluded that the performance of OLEDs with metal anodes is poorer than those OLEDs with ITO anodes. However, the metals of Au and Pt with proper surface treatment on non-ITO electrodes, such as $\mathrm{Si}$ and $\mathrm{Al}$, have been reported to improve the performance of top emission OLEDs [19], [20] but no obvious studies on ITO electrodes for bottom emission OLEDs.

In this brief, we use $\mathrm{V}_{2} \mathrm{O}_{5}$ coating on transparent thin $\mathrm{Au}$ film as a composite hole-injection layer on ITO anode for bottom emitting OLEDs. The characteristics of bottom emitting OLEDs with the composite anodes of ITO- $\mathrm{Au}-\mathrm{V}_{2} \mathrm{O}_{5}$ are described. A thin oxide layer $\mathrm{V}_{2} \mathrm{O}_{5}$ is used to modify the surface of $\mathrm{Au}$ for enhancing the hole injection from $\mathrm{Au}$ by the increase of work function to $5.3 \mathrm{eV}$ and thus sequentially improves emission efficiency. The effects of $\mathrm{V}_{2} \mathrm{O}_{5}$ layer on the enhancement of electrical properties of the bottom emitting OLEDs are discussed. Ultraviolet and X-ray photoelectron spectroscopy (UPS and XPS, respectively) analysis indicate that the higher work function of ITO/Au/ $/ \mathrm{V}_{2} \mathrm{O}_{5}(5.3 \mathrm{eV})$ than ITO/Au $(5.0 \mathrm{eV})$ anode is due to Au surface band bending. Thus, the barrier for hole injection from ITO through $\mathrm{Au} / \mathrm{V}_{2} \mathrm{O}_{5}$ to the hole transport layer (HTL) is decreased. Our results show that the performance of OLEDs with $\mathrm{V}_{2} \mathrm{O}_{5}$ layer is greatly improved compared with the case of only Au layer on the ITO. Interestingly, it is also better than the ITO anode modified by $\mathrm{V}_{2} \mathrm{O}_{5}$ device.

All devices were fabricated on ITO coated glass with a sheet resistance of $10 \Omega / \square$, and thermally deposited LiF/Al was used as cathode. ITO substrate was cleaned and treated by $\mathrm{O}_{2}$ plasma. The deposition was carried out at a pressure of less than $3 \times 10^{-4} \mathrm{~Pa}$ without any vacuum break. The organics and metal oxide were evaporated at the rate in a range of $0.3-0.4 \mathrm{~nm} / \mathrm{s}$. The Au metals were evaporated at the rate of $\sim 0.1 \mathrm{~nm} / \mathrm{s}$ prior to the oxide and organic layer deposition. Al metal was evaporated at the rate of $0.3 \sim 0.5 \mathrm{~nm} / \mathrm{s}$. The devices have an emissive area of $3.57 \mathrm{~mm}^{2}$. The organic layers consisted of $\quad 70-\mathrm{nm} \quad 4,46^{\prime}-\mathrm{N}, \mathrm{N}^{\prime}$-bis[N-(1-naphthyl)-N-phenyl-amino] 
biphenyl (NPB) as the HTL, 50-nm tris(8-hydrooxyquinoline) aluminum $\left(\mathrm{Alq}_{3}\right)$ as the electron transport layer, and emissive layer. The bilayer of $\mathrm{LiF} / \mathrm{Al}$ was used as the efficient electron injection cathode. The structure of the device is $\mathrm{ITO} / \mathrm{Au}(6 \mathrm{~nm}) / \mathrm{V}_{2} \mathrm{O}_{5}(5 \mathrm{~nm}) / \mathrm{NPB}(70 \mathrm{~nm}) / \mathrm{Alq}_{3}(50 \mathrm{~nm}) /$ $\mathrm{LiF}(1 \mathrm{~nm}) / \mathrm{Al}(70 \mathrm{~nm})$. For comparison, another three devices were fabricated. These three devices had the same organic and electron injection structure as the one just described, except that $\mathrm{Au}$ on the ITO without $\mathrm{V}_{2} \mathrm{O}_{5}$ coating, ITO coated with $\mathrm{V}_{2} \mathrm{O}_{5}$, and bare ITO were used as the anodes.

The current-voltage-brightness characteristics were recorded using a computer controlled source meter (Keithley 2400) and photometer (IL1400A) with a calibrated silicon photodiode. The EL spectra were measured by Instaspec spectrometer. All measurements were carried out in ambient atmosphere at room temperature. The UPS of samples was measured with He discharge lamp (UV light of $21.2 \mathrm{~V}$; Thermo Electron Corporation, ESCALAB 250). The XPS measurements were carried out with LargeAreaXL surface analysis system using a monochromatic Al K Alpha source.

The $J-V$ characteristics of the four devices with ITO $/ \mathrm{Au} / \mathrm{V}_{2} \mathrm{O}_{5}$, ITO/Au, ITO $/ \mathrm{V}_{2} \mathrm{O}_{5}$, and bare ITO anodes are shown in Fig. 1(a). The devices with the ITO/Au and bare ITO anodes show poor hole injection. However, by adding a layer of $\mathrm{V}_{2} \mathrm{O}_{5}$ with a thickness of $6 \mathrm{~nm}$, the $J-V$ characteristics of the device with ITO $/ \mathrm{V}_{2} \mathrm{O}_{5}$ and ITO/Au/ $/ \mathrm{V}_{2} \mathrm{O}_{5}$ anodes are dramatically improved as compared with the previous two OLED structures without $\mathrm{V}_{2} \mathrm{O}_{5}$. For example, the current density of OLEDs with the ITO/Au and ITO/Au/ $/ \mathrm{V}_{2} \mathrm{O}_{5}$ anodes at $11 \mathrm{~V}$ are 0.065 and $69 \mathrm{~mA} / \mathrm{cm}^{2}$, respectively. Fig. 1(b) shows that, at the same applied voltage, the luminance of the OLED with the ITO/Au/ $/ \mathrm{V}_{2} \mathrm{O}_{5}$ anode is much larger than that of the device with the ITO/Au anode. The driving voltage for a given current or a given luminance of the OLED with the $\mathrm{ITO} / \mathrm{Au} / \mathrm{V}_{2} \mathrm{O}_{5}$ anode is significantly decreased by $\sim 10 \mathrm{~V}$ as compared with that of the ITO/Au OLED due to $\mathrm{V}_{2} \mathrm{O}_{5}$ layer modification.

The current efficiency versus the current density of OLEDs is shown in Fig. 1(c). It can be seen that the maximum current efficiency of the ITO/Au/ $/ \mathrm{V}_{2} \mathrm{O}_{5}$ OLED $(\sim 3.5 \mathrm{~cd} / \mathrm{A})$ is three times more than that of the ITO/Au anode device $(\sim 1.1 \mathrm{~cd} / \mathrm{A})$. The results are attributed to the $\mathrm{V}_{2} \mathrm{O}_{5}$ modification layer. The existence of $\mathrm{V}_{2} \mathrm{O}_{5}$ increases the hole injection to HTL and thus increases the number of excitons at the interface of $\mathrm{NPB} / \mathrm{Alq}_{3}$. At the same time, the optical transmittance of ITO/Au/ $/ \mathrm{V}_{2} \mathrm{O}_{5}$ is higher than that of ITO/Au, as shown in Fig. 2, which is also one of the reasons for increasing the current efficiency. However, the optical transmittance of ITO/Au $/ \mathrm{V}_{2} \mathrm{O}_{5}$ is lower than that of ITO $/ \mathrm{V}_{2} \mathrm{O}_{5}$, as shown in Fig. 2; the current efficiency of the ITO/Au $/ \mathrm{V}_{2} \mathrm{O}_{5}$ OLED $(\sim 3.5 \mathrm{~cd} / \mathrm{A})$ is still higher than ITO $/ \mathrm{V}_{2} \mathrm{O}_{5}$ OLED $(\sim 2.8 \mathrm{~cd} / \mathrm{A})$. Together with the $J-V$ results of the ITO/Au $/ \mathrm{V}_{2} \mathrm{O}_{5}$ OLED, as discussed previously, the higher current efficiency of ITO/Au/ $/ \mathrm{V}_{2} \mathrm{O}_{5}$ OLED than ITO $/ \mathrm{V}_{2} \mathrm{O}_{5}$ OLED is attributed to the better charge balance [21]. Moreover, the improved current efficiency is not likely due to the microcavity effect [22] in the device with $\mathrm{ITO} / \mathrm{Au} / \mathrm{V}_{2} \mathrm{O}_{5}$ anode because there is no change in electroluminescence spectrum (not shown in this brief).
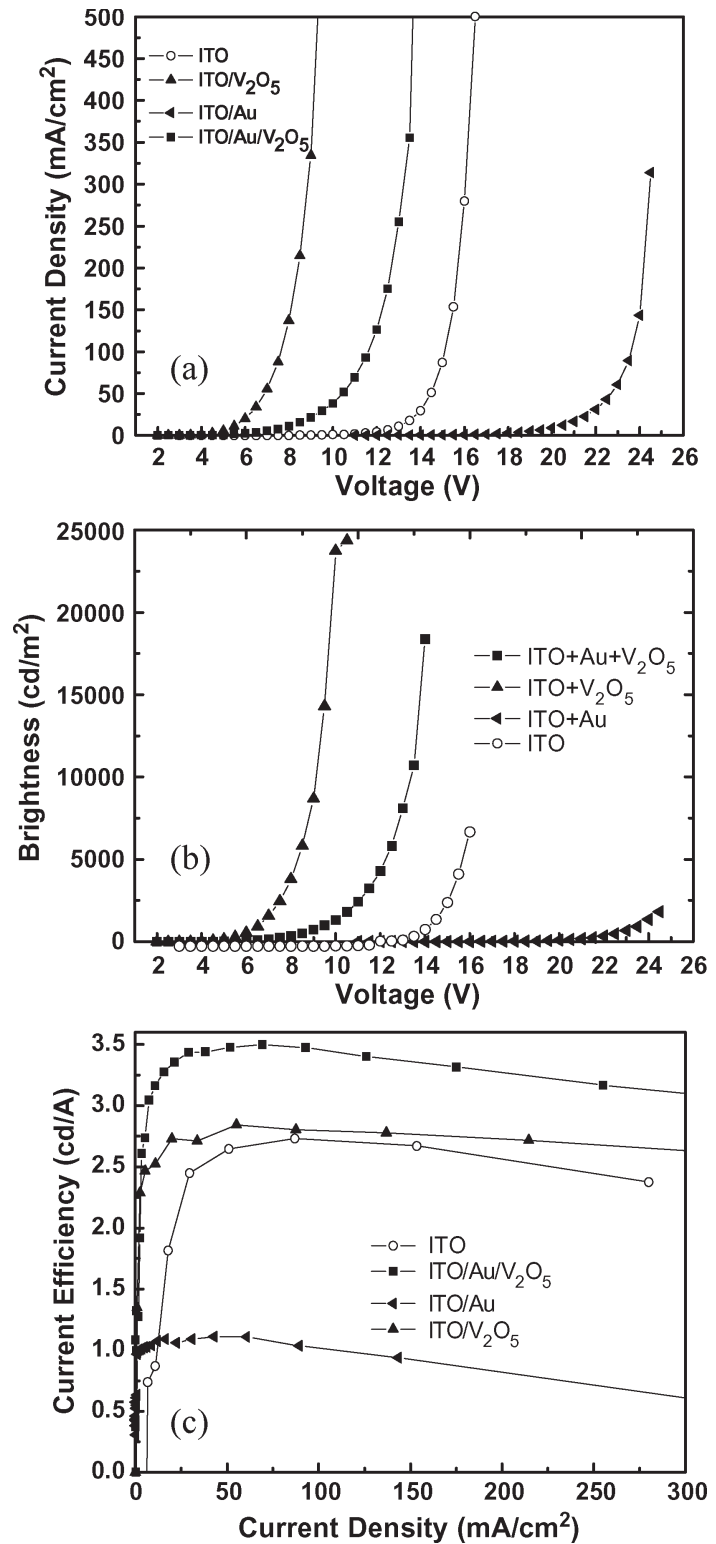

Fig. 1. (a) $J-V$, (b) $L-V$, and (c) current efficiency characteristics of OLEDs with ITO/Au $/ \mathrm{V}_{2} \mathrm{O}_{5}$, ITO/Au, ITO/ $\mathrm{V}_{2} \mathrm{O}_{5}$, and bare ITO anodes.

The reduction of operation voltage can be explained by lowering the barrier of hole injection from anode to HTL. The UPS was used to measure the work function. The UPS spectra of $\mathrm{V}_{2} \mathrm{O}_{5}, \mathrm{Au}$, and $\mathrm{Au} / \mathrm{V}_{2} \mathrm{O}_{5}$ on ITO, as well as bare ITO, are shown in Fig. 3. From the UPS spectra, the work function of ITO is determined to be $4.7 \mathrm{eV}$. This value is consistent with the commonly accepted values [23]. The measured work functions of the other ITO surfaces modified by $\mathrm{V}_{2} \mathrm{O}_{5}, \mathrm{Au}$, and $\mathrm{Au} / \mathrm{V}_{2} \mathrm{O}_{5}$ are $5.1,5.0$, and $5.3 \mathrm{eV}$, respectively. From these measured data, we observe that there are about $0.4-$ and $0.3-\mathrm{eV}$ increases in the work functions of ITO and ITO/Au surfaces treated by $\mathrm{V}_{2} \mathrm{O}_{5}$, respectively. The results indicate that the barrier for hole injection from ITO $/ \mathrm{V}_{2} \mathrm{O}_{5}$ and ITO/Au/ $/ \mathrm{V}_{2} \mathrm{O}_{5}$ anodes is decreased. Meanwhile, although the work function of $\mathrm{Au}$ is higher that of bare ITO, the existence of an interface dipole at the Au-NPB interface results in a large hole-injection barrier of $1.35 \mathrm{eV}$, which virtually blocks the hole injection [18]. 


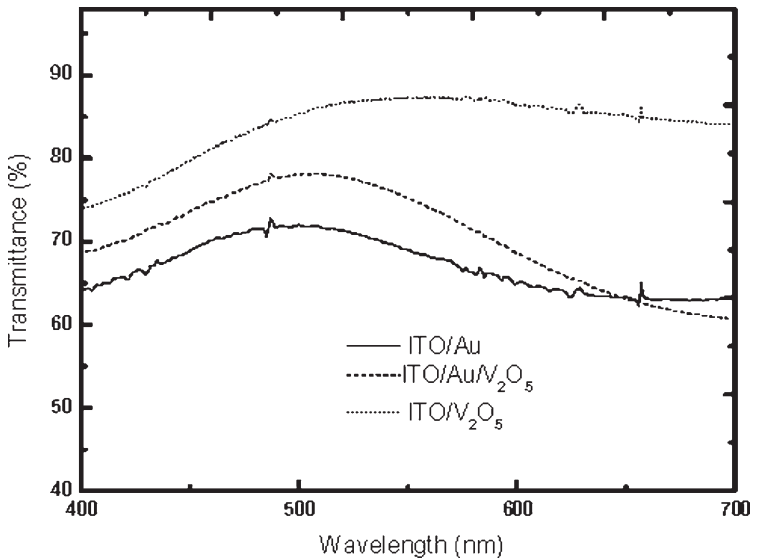

Fig. 2. Transmittance spectra of ITO/Au/ $/ \mathrm{V}_{2} \mathrm{O}_{5}$, ITO/Au, and ITO $/ \mathrm{V}_{2} \mathrm{O}_{5}$.

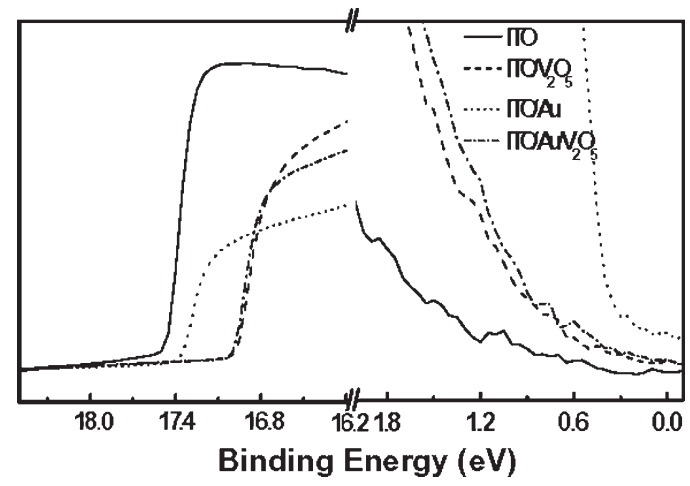

Fig. 3. UPS spectra of ITO (solid line), ITO $/ \mathrm{V}_{2} \mathrm{O}_{5}$ (dash line), ITO/Au (dot line), and ITO/Au $/ \mathrm{V}_{2} \mathrm{O}_{5}$ (dash dot line).

Fig. 4 shows the XPS wide scan data spectra of the bare ITO, ITO $/ \mathrm{V}_{2} \mathrm{O}_{5}$, ITO/ $\mathrm{Au}$, and ITO/Au $/ \mathrm{V}_{2} \mathrm{O}_{5}$ anodes. In Fig. 4(a), strong $\mathrm{O} 1 s$, In $3 d$, and $\mathrm{Sn} 3 d$ peaks are obtained, which are attributed to the ITO anode layer. The fairly strong $\mathrm{C} 1 s$ peak corresponded to the existence of organic contamination on the ITO anode. The results are similar to the reported ones [24]. By comparing the ITO $/ \mathrm{V}_{2} \mathrm{O}_{5}$ case in Fig. 4(b) with the bare ITO case in Fig. 4(a), the additional V $2 p$ peak and the stronger $\mathrm{O} 1 s$ peak of the ITO $/ \mathrm{V}_{2} \mathrm{O}_{5}$ case than that of the bare ITO are observed, apart from a slightly left shift of the peak position. It is also quite evident that the peak intensities of In $3 d$ and Sn $3 d$ (electron donor) are dramatically reduced on ITO surfaces treated by $\mathrm{V}_{2} \mathrm{O}_{5}$. These results are attributed to the modifications of $\mathrm{V}_{2} \mathrm{O}_{5}$ on ITO anode, which contributes to the enhancement of hole injection [1], [12]. The XPS of ITO/Au [Fig. 4(c)] is similar to that of bare ITO anode [Fig. 4(a)] except the additional peaks of $\mathrm{Au} 4 d$ and $\mathrm{Au} 4 f$, i.e., no modification effect on the ITO surface. Therefore, Au on ITO cannot provide better hole injection, which is agreed with [18]. The XPS of ITO/Au $/ \mathrm{V}_{2} \mathrm{O}_{5}$ [Fig. 4(d)] shows a similar spectrum to ITO $/ \mathrm{V}_{2} \mathrm{O}_{5}$ [Fig. 4(b)] except the additional $\mathrm{Au} 4 d$ and $\mathrm{Au} 4 f$ peaks. This implies that $\mathrm{V}_{2} \mathrm{O}_{5}$ buffer layer offers modification effects on ITO/Au surface. Due to the composite anode of ITO and Au formed, the energy level difference exists between the ITO $(4.7 \mathrm{eV})$ and $\mathrm{Au}(5.0 \mathrm{eV})$ interface; the device with ITO $/ \mathrm{V}_{2} \mathrm{O}_{5}$ anode exhibited better $J-V$ performance than the one with ITO/Au/ $/ \mathrm{V}_{2} \mathrm{O}_{5}$ anode. It is also possible that $\mathrm{Au}$ as

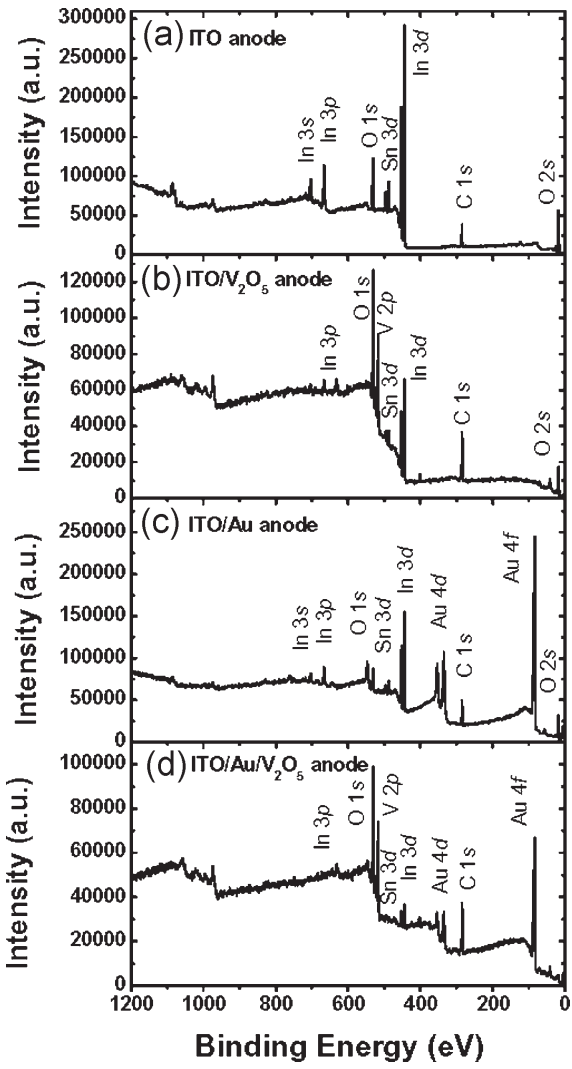

Fig. 4. XPS wide scan spectrum of (a) bare ITO anode film, (b) ITO $/ \mathrm{V}_{2} \mathrm{O}_{5}$ anode film, (c) ITO/Au anode film, and (d) ITO/Au/ $/ \mathrm{V}_{2} \mathrm{O}_{5}$ anode film.

a block layer that makes ITO/Au $/ \mathrm{V}_{2} \mathrm{O}_{5}$ OLED has a better charge balance. Consequently, the current efficiency of the ITO/Au $/ \mathrm{V}_{2} \mathrm{O}_{5}$ OLED $(\sim 3.5 \mathrm{~cd} / \mathrm{A})$ is higher than ITO $/ \mathrm{V}_{2} \mathrm{O}_{5}$ OLED $(\sim 2.8 \mathrm{~cd} / \mathrm{A})$.

In summary, we show that ITO/Au/ $/ \mathrm{V}_{2} \mathrm{O}_{5}$ composite electrode can be used as an effective anode for bottom emitting OLEDs. Hole injection is virtually blocked when $\mathrm{Au}$ is added on ITO as an anode. Interestingly, while an additional layer of $\mathrm{V}_{2} \mathrm{O}_{5}$ is introduced on $\mathrm{Au}$ surface, the hole injection is greatly enhanced. It is attributed to a lower energy level difference at the anode/organic interface. In addition, the device with ITO/Au $/ \mathrm{V}_{2} \mathrm{O}_{5}$ as anode provides a better charge balance, which makes the current efficiency of the ITO $/ \mathrm{Au} / \mathrm{V}_{2} \mathrm{O}_{5}$ OLED $(\sim 3.5 \mathrm{~cd} / \mathrm{A}) 1.25$ times higher than that of the ITO $/ \mathrm{V}_{2} \mathrm{O}_{5}$ OLED $(\sim 2.8 \mathrm{~cd} / \mathrm{A})$.

\section{REFERENCES}

[1] M. G. Mason, L. S. Hung, C. W. Tang, S. T. Lee, K. W. Wong, and M. Wang, "Characterization of treated indium-tin-oxide surfaces used in electroluminescent devices," J. Appl. Phys., vol. 86, no. 3, pp. 1688-1692, Aug. 1999.

[2] H. Y. Yu, X. D. Feng, D. Grozea, R. N. S. Sodhi, A.-M. Hor, H. Aziz, and Z. H. Lu, "Surface electronic structure of plasma-treated indium tin oxides," Appl. Phys. Lett., vol. 78, no. 17, pp. 2595-2597, Apr. 2001.

[3] Y. Y. Yuan, S. Han, D. Grozea, and Z. H. Lua, "Fullerene-organic nanocomposite: A flexible material platform for organic light-emitting diodes," Appl. Phys. Lett., vol. 88, no. 9, pp. 093 503-1-093 503-3, Feb. 2006.

[4] E. W. Forsythe, Y. L. Gao, and M. A. Abkowitz, "Tuning the carrier injection efficiency for organic light-emitting diodes," J. Phys. Chem., vol. 104, no. 16, pp. 3948-3952, 2000. 
[5] T. Matsushima and C. Adachi, "Enhanced hole injection and transport in molybdenum-dioxide-doped organic hole-transporting layers," J. Appl. Phys., vol. 103, no. 3, pp. 034 501-1-034 501-8, Feb. 2008.

[6] S. A. Van Slyke, C. H. Chen, and C. W. Tang, "Organic electroluminescent devices with improved stability," Appl. Phys. Lett., vol. 69, no. 15, pp. 2160-2162, Oct. 1996.

[7] P. K. H. Ho, J. S. Kim, J. H. Burroughes, H. Becker, S. F. Y. Li, T. M. Brown, F. Cacialli, and R. H. Friend, "Molecular-scale interface engineering for polymer light-emitting diodes," Nature, vol. 404, no. 6777, pp. 481-484, Mar. 2000.

[8] J. M. Moon, J. H. Bae, J. A. Jeong, S. W. Jeong, N. J. Park, J. W. Kang, J. J. Kim, M. S. Yi, and H. K. Kim, "Enhancement of hole injection using ozone treated $\mathrm{Ag}$ nanodots dispersed on indium tin oxide anode for organic light emitting diodes," Appl. Phys. Lett., vol. 90, no. 16, pp. 163 516-1-163 516-3, Apr. 2007.

[9] H. Kanno, Y. Sun, and S. R. Forrest, "High-efficiency top-emissive whitelight-emitting organic electrophosphorescent devices," Appl. Phys. Lett., vol. 86, no. 26, pp. 263 502-1-263 502-3, Jun. 2005.

[10] A. Chakrabarti, K. Hermann, R. Druzinic, M. Witko, F. Wagner, and M. Petersen, "Geometric and electronic structure of vanadium pentoxide: A density functional bulk and surface study," Phys. Rev. B, Condens. Matter, vol. 59, no. 16, pp. 10583-10 590, Apr. 1999.

[11] K. Hermann, M. Witkoq, R. Druzinic, A. Chakrabarti, B. Tepper, M. Elsner, A. Gorschluter, H. Kuhlenbeck, and H. J. Freund, "Properties and identification of oxygen sites at the $\mathrm{V}_{2} \mathrm{O}_{5}(010)$ surface: Theoretical cluster studies and photoemission experiments," J. Electron Spectrosc. Relat. Phenom., vol. 98/99, pp. 245-256, Jan. 1999.

[12] E. L. Bruner, N. Koch, A. R. Span, S. L. Bernasek, A. Kahn, and J. Schwartz, "Controlling the work function of indium tin oxide: Differentiating dipolar from local surface effects," J. Amer. Chem. Soc., vol. 124, no. 13, pp. 3192-3193, Apr. 2002.

[13] X. L. Zhu, J. X. Sun, H. J. Peng, Z. G. Meng, M. Wong, and H. S. Kwok, "Vanadium pentoxide modified polycrystalline silicon anode for activematrix organic light-emitting diodes," Appl. Phys. Lett., vol. 87, no. 15, pp. $153508-1-153508-3$, Oct. 2005.

[14] C. W. Chen, P. Y. Hsieh, H. H. Chiang, C. L. Lin, H. M. Wu, and C. C. Wu, "Top-emitting organic light-emitting devices using surfacemodified Ag anode," Appl. Phys. Lett., vol. 83, no. 25, pp. 5127-5129, Dec. 2003

[15] S. Han, Y. Yuan, and Z. H. Lu, "Highly efficient organic light-emitting diodes with metal/fullerene anode," J. Appl. Phys., vol. 100, no. 7, pp. 074 504-1-074 504-6, Oct. 2006.

[16] I. G. Hill, A. Rajagopal, A. Kahn, and Y. Hu, "Molecular level alignment at organic semiconductor-metal interfaces," Appl. Phys. Lett., vol. 73, no. 5, pp. 662-664, Aug. 1998.

[17] H. Ishii, K. Sugiyama, E. Ito, and K. Seki, "Energy level alignment and interfacial electronic structures at organic/metal and organic/organic interfaces," Adv. Mater, vol. 11, no. 8, pp. 605-625, 1999.

[18] J. X. Tang, Y. Q. Li, L. R. Zheng, and L. S. Hung, "Anode/organic interface modification by plasma polymerized fluorocarbon films," J. Appl. Phys., vol. 95, no. 8, pp. 4397-4403, Apr. 2004
[19] G. Z. Ran, Y. H. Xu, G. L. Ma, A. G. Xu, Y. P. Qiao, W. X. Chen, and G. G. Qin, "Organic light-emitting diodes with n-type silicon anode," Semicond. Sci. Technol., vol. 20, no. 8, pp. 761-764, Aug. 2005.

[20] C. F. Qiu, H. J. Peng, H. Y. Chen, Z. L. Xie, M. Wong, and H. S. Kwok, "Top-emitting OLED using praseodymium oxide coated platinum as hole injectors," IEEE Trans. Electron Devices, vol. 51, no. 7, pp. 1207-1210, Jul. 2004.

[21] H. H. Fong, W. C. H. Choy, K. N. Hui, and Y. J. Liang, "Organic lightemitting diodes based on a cohost electron transporting composite," Appl. Phys. Lett., vol. 88, no. 11, pp. 113 510-1-113 510-3, Mar. 2006.

[22] W. C. H. Choy and C. Y. Ho, "Improving the viewing angle properties of microcavity OLEDs by using dispersive gratings," Opt. Express, vol. 15, no. 20, pp. 13288-13 294, Oct. 2007.

[23] Y. Park, V. Choong, Y. Gao, B. R. Hsieh, and C. W. Tang, "Work function of indium tin oxide transparent conductor measured by photoelectron spectroscopy," Appl. Phys. Lett., vol. 68, no. 19, pp. 2699-2701, May 1996.

[24] J. M. Moon, J. H. Bae, J. A. Jeong, S. W. Jeong, N. J. Park, and H. K. Kim, "Enhancement of hole injection using ozone treated Ag nanodots dispersed on indium tin oxide anode for organic light emitting diodes," Appl. Phys. Lett., vol. 90, no. 16, pp. 163516-1-163516-3, Apr. 2007.

H. M. Zhang, photograph and biography not available at the time of publication.

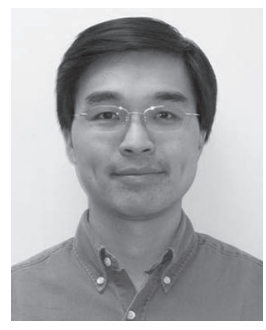

Wallace C. H. Choy (SM'07) received the Ph.D. degree in electronic engineering from the University of Surrey, Surrey, U.K.

His work at Surrey was supported by the Croucher Foundation Scholarship. In 1999, he was with the National Research Council of Canada as a member of the research staff, working, both theoretically and experimentally, on polarization-independent optical amplifiers and modulators. He was with Fujitsu Compound Semiconductor, Inc., San Jose, CA, in 2001, developing wavelength tunable lasers and high-speed transmitter modules. He is a Research Assistant Professor with the Department of Electrical and Electronic Engineering, The University of Hong Kong, Hong Kong, and currently a Visiting Professor with the Department of Materials Science and Engineering, Cornell University, Ithaca, NY. He has published over 60 internationally technical journal papers and contributed to two book chapters. His current research interests are concerned with organic optoelectronic devices, nanomaterial devices, and photonic integrated circuit.

Dr. Choy received the Outstanding Achievement Award from NRC in 2001. 